\title{
Matematik Eğitiminde Kavram Yanlışlıkları Üzerine
}

\author{
Zekeriya GÜNEY \\ Muğla Sttkı Koçman Üniversitesi Ĕgitim Fakültesi, Ortaögretim Fen/Matematik Alanlar Eğitimi \\ Bölümü, Matematik Eğitimi ABD 48000 Menteşe/MUĞLA \\ e-mail:zguney@mu.edu.tr \\ Murad ÖZKOÇ \\ Muğla Sttkr Koçman Üniversitesi Fen Fakültesi, Matematik Bölümü 48000 Menteşe/MUĞLA \\ e-mail: murad.ozkoc@mu.edu.tr \\ Nebiye KORKMAZ \\ Muğla Sttkı Koçman Üniversitesi Eğitim Fakültesi, \\ Illköğretim Bölümü, Matematik Eğitimi ABD 48000 Menteşe/MUĞLA \\ e-mail:nkorkmaz@mu.edu.tr
}

\begin{abstract}
$\ddot{O}_{z e t}$
Bu çalışmada, liselerde bazı matematik kavramlarının ögrencilere anlatımında yapılan hatalar örneklerle açılklanmaya çalışılmış̧ır. Lise matematik derslerinin işlenilişinde, mantık, dil, yöntem, simge kullanımı, kavram bilgisi, vb. gibi birçok bakımlardan önemli boyutlarda olumsuzluklar gözlenmistir. Elde edilen verilere, lise ders kitaplarının taranması, OFMA pedagojik formasyon programları, uygulama gözlemleri vb. gibi etkinliklerle ulaşılmıştır. Genel olarak matematik ögretmenlerinin ders kitaplarındaki yanlışlıklara dikkat etmedikleri ve dersleri işlerken gerekli düzeltmeleri yapmadıları gözlenmiştir.
\end{abstract}

Anahtar Kelimeler: Mantı, Formalizm, OFMA pedagojik formasyon programlart.

\section{On the Concept of Inaccuracies in Mathematics Education}

\begin{abstract}
In this study, mistakes made in the expression of some of the mathematical concepts for the high school students are tried to be explained with some examples. Significant negative effects have been observed in many ways such as logic, language, methods, the use of symbols, concept knowledge, etc. The obtained data has been reached through activities such as screening of school textbooks, Secondary pedagogical programs, application observations. Generally, it is observed that mathematics teachers do not pay attention to the mistakes in textbooks and do not make the necessary corrections while they are processing the lesson.
\end{abstract}

Keywords: Logic, Formalism, Secondary pedagogical programs.

\section{Matematikte Simge Kullanmanın Önemi}

\subsection{Matematiksel Kesinliğe Dair}

Matematiksel söylemler, pratik değeri düşük olmalarına karşın, kesinlik tutkunları için büyük değer taşırlar. Matematiksel kesinlik, mutlak bir kesinlik olmayıp görecelidir. Matematiği (ya da matematikçileri) diğer alanlardan (ya da diğerlerinden) ayıran üç temel 
prensip vardır: 1. Pür matematikçi "eğer $p$ doğruysa o zaman $q$ da doğrudur" savının geçerli olup olmadığıyla ilgilenir (Güney, 2013). 2. Matematikte, tanımlar varsayımlarla uyum içinde olmalı; yeni bir teoremin ispatında yalnız ve yalnız tanımlar varsayımlar ve daha önceden ispatlanmış teoremler kullanılmalıdır. Yani fazlalık ya da laf kalabalığı olmamalı ve en küçük bir şüphe de bulunmamalıdır. 3. Aksiyomlar, tanımlar, teoremler ve bunların ispatları ifade edilirken kesinlik zorunluluğu vardır. Matematik ardışık ve yığmalı bir aşamalar dizisidir ve akıl yürütme yoluyla yeni soyut gerçekleri ortaya çıkarır. Ulaşılan yeni bilgiler daha önceden bilinenlerin ya da doğru olduğu varsayılan öncüllerin, zorunlu mantıksal sonuçlarıdır ve deney-gözlemden bağımsız bir kesinlik içerirler. Bazı eğitimciler, mesleklerinin olağanüstü bir güce sahip olduğuna inandıklarından olsa gerek (!), matematik öğretmenleri için (hatta herhangi bir alan öğretmeni için) pedagojik formasyonun alan bilgisinden daha önce geldiğini savunuyorlar. Fakat böylece de "bir şeyi öğretebilmenin olmazsa olmaz koşulu o şeyi bilmektir" ilkesini göz ardı etmiş oluyorlar. Bazı eğitimciler "mazruf”a değil zarfa bakıyorlar!.. Çeşit çeşit, renkli renkli, güzel güzel zarflar hazırlamayı pek seviyorlar. Eğitim sistemlerimizin mimarları olan eğitimcilerimiz daha iyisi olsun, daha iyisi olsun diye ikide bir program değişikliği yaparlar. II. milenyuma girerken de, böyle bir program değişikliği gerçekleştirmiş̧ler ve bilim adamlarının bütün direnmelerine rağmen eğitim fakültelerinin matematik bölümlerindeki matematik derslerini yarı yarıya tırpanlayarak yerlerine pedagojik formasyon dersleri koymuşlardı. Şimdi bazı matematik öğretmenlerinin matematik bilgilerinin yetersizliğinden yakınıyoruz!.. "Matematik ya kesindir ya da bir hiçtir" (King, 1999). Son yıllarda, matematikçilikten gelmeyen, bu nedenle de matematiğin değerinin nerede olduğunu karıştıran, fakat matematik eğitimi konusunda söz sahibi görünen bazı eğitimcilerin, kuşkusuz iyi niyetle önerdikleri ve uygulattırdıkları, fakat matematiğin tümdengelimsel doğası ile uyuşmayan, lise matematik program ve yöntemleri ne yazık ki bu hiçliği temsil etmektedir. Önerilen açıkça şudur: Kavramlar kolaylaşsın; fizik ve sosyal bilimlerdeki gibi tümevarımsal yöntemlerle öğrenci kavramları kendi oluştursun; varsın kafalarına yerleştirdikleri kavram asıl pür matematikteki gerçek kavramın tam karşıllğ 1 olmasın fakat yaşamsal olguları çağrıştırsın; biraz muğlak olsa da öğrenci kafasına göre bir şeyler algılasın; kafayı zorlayan akıl yürütmelerden uzak durulsun ki matematiği sevsinler; biraz daha pratiklik, gerçek yaşama uygulanabilirlik daha iyidir. Tamam yapın! Fakat buna matematik demeyin! Otomatik, paramatik, bankamatik, vs. deyin ama matematik demeyin... Böyle bir sözüm ona matematik terbiyesi almış öğrencilerden, gerçek matematik eğitimi almış öğrencilerden beklenen davranışları beklemeyin. Öğrencilerin doğru ile yanlışı ayırt edebilmelerini, demagoji değil doğru akıl yürütme yapabilmelerini, körü körüne ya da kafasına göre ya da işine geldiği gibi değil fakat kurallara hakka hukuka saygılı davranışlar göstermelerini beklemeyin. Matematiğe gerçekten yatkın öğrencilerin de bu eğitim yüzünden körelmeyip ilerde büyük matematikçiler olmalarını beklemeyin. Matematiğin yöntemi tümdengelimdir. Matematik öğretmek için matematikten vazgeçilmez! Kavramların kesin tanımları verildikten sonra, anlamakta zorlanan öğrenciler için türlü türlü önlemler alınabilir, bol bol örnekler üzerinde çalışılabilir, özveri gerektiren çalışmalar yapılabilir; fakat onlar anlasın diye ayrı bir matematik uydurulamaz. "Krallar için (ya da geç anlayanlara özgü) ayrı matematik yoktur (Euclid-Eukleídēs, M.Ö. 330-M.Ö. 275)" (Güney, Paşalı, Özsot ve Koçak, 2013). Tümdengelimsel aksiyomatik bir disiplin olan matematiğin doğasına ters bir anlayışla, matematiğin konularını günlük yaşam olgularıyla ilişkilendirerek, doğa bilimlerinin ve sosyal bilimlerin tümevarımsal yöntemleriyle işlemeye kalkışılmak ve buna da "Yapılandırmacı Öğrenme Yaklaşımı" diyerek, öğrencinin matematiksel kavramları daha kolay anlayacağı ve kalıcı olacağı savını savunmak büyük bir hatadır. Yapılan şudur: Öğrenci ne yaptığını neye ulaşmaya çalıştığını bilmeden birtakım çalışmalara itiliyor; diyelim "birim (etkisiz) eleman" kavramını kavratmak için, bu kavrama dair öğrenciye -hadi tanımdan vazgeçtik- hiçbir 
ipucu verilmeden, ne amaçla uğraştıkları bildirilmeden "illallah" dedirtecek bir takım çalışmalar yaptırılarak, öğrenci sanki "kahin”miş gibi, "şimdi etkisiz eleman ne demekmiş anladınız değil mi?" diye soruluyor. Sonra da, bunu şöyle ifade ederiz diye yarım yamalak sözüm ona bir tanım veriliyor: "Bir $A$ kümesinde tanımlı " $\Delta$ " işleminin etkisiz elemanı $e$ olduğuna göre $\forall x \in A$ için $x \Delta e=e \Delta x=x$ olduğunu fark ettiniz mi?". Hemen tüm kavramları anlatmak için baştan sona böyle devam ediliyor ve matematik "katlediliyor"!.. Başka bir örnek olarak, ters eleman kavramı, bir komisyon tarafindan hazırlanan 9. sınıf matematik ders kitabında, -“ters eleman” sözcükleri hiç anılmadan öğrenciye birkaç işlem yaptırıldıktan sonra- aynen şöyle anlatılmıştır: "Bir kümede tanımlı bir işleme göre herhangi bir eleman, tersi ile işleme girdiğinde sonucun işlemin etkisiz elemanını verdiğini fark ettiniz mi? Bu durum, bir $A$ kümesinde tanımlı "*" işleminin etkisiz elemanı " $e$ " ve herhangi bir $x$ elemanının " $*$ " işlemine göre tersi $x^{-1}$ olmak üzere, $x * x^{-1}=x^{-1} * x=e$ şeklinde ifade edilir." Bu sözde tanımlar için kullanılan dil sintaktik kurallara uymamakta ve matematiksel dilin kesinlik, mantıksallık, dakiklik ve evrensellik özelliklerinden uzak bulunmaktadır. Kaldı ki, baştan sona tüm konular matematiğin tümdengelimsel yöntemiyle değil, sanki fizik ya da sosyal bilimler çalışılıyormuş gibi tümevarımsal yöntemle işlenmektedir. Kavramların ne anlama geldikleri ve hatta isimleri (terimler) bile öğrenciye buldurulmaya çalışılmaktadır. Öğrenciler ne amaçla neye ulaşmak için çalıştıklarını bilmeden birtakım ödevler yapmakta ve sonra da kafaları karmakarışık haldeyken onlardan adlarını bile duymadıkları kavramların tanımlarına ulaşmaları beklenmektedir. Oysa çalışmaların sonunda kendi yaptıkları bu sözde tanımlardaki yanlışlık ve eksikliklerden açıça belli oluyor ki, söz konusu kavramlar yazarların kafalarına bile tam olarak yerleşmemiştir. $O$ halde öğrencilerin mantıklı akıl yürütme yapamamalarına şaşmamalıyız. Doğrusu çok nettir; bir $(A, *)$ grubunda birim eleman ve ters eleman özellikleri, tüm ulusal dillerden bağımsız olarak matematiğin evrensel simgeleriyle aşağıdaki gibi yazılır:

(Güney, 2006; Güney, 2007).

$$
\begin{aligned}
& \exists e \in A, \forall x \in A, x * e=e * x=x \\
& \forall x \in A, \exists y \in A, x * y=y * x=e
\end{aligned}
$$

$\mathrm{Bu}$ sintaktik önermelerde geçen $\exists$ ve $\forall$ gibi simgelerin tanımları, kullanılışları, kullanım sırası değiştiğinde ifade edilen anlamın nasıl değiştiği vb. her türlü matematik çalışması için lojistik oluşturan matematiksel mantık konusunda incelenir. Matematiksel sembolik mantık, lise 1 matematik ders konularının başında yer alır; ancak çoğu matematik öğretmenleri ve matematik kitabı yazarları bu konunun daha sonraki konular için temel oluşturduğunu göz ardı ederek "üstünkörü" işlemekte ve adeta sanki sonraki konulardan bağımsız bir konuymuş gibi ele almaktadırlar. Kavramların tanımlanmasında ve birbirleriyle ilişkilendirilmesinde, teoremlerin ifadelerinde ve ispatlarında, varsayım ve kanıtlanmış teoremlerden hareketle yeni bilgilere ulaşmak için yapılan akıl yürütmelerde sürekli matematiksel mantık kullanmaları gerektiği halde hemen her zaman bunu göz ardı etme gafletine düşerler. Böylece matematiği de matematik olmaktan çıkarıp, sıradan, muğlak, anlaşılmaz, sevimsiz ve itici bir hale getirirler. Matematik öğretmek için matematikten vazgeçilmez! Kavramların kesin tanımlarını verdikten sonra, anlamakta zorlanan öğrenciler için türlü türlü önlemler alabilir, bol bol örnekler üzerinde çalışabilirsiniz, özveri gerektiren çalışmalar yapabilirsiniz, fakat onlar anlasın diye ayrı bir matematik uyduramazsınız. Matematiğin tümdengelimli aksiyomatik yapısını göz ardı edemezsiniz (Güney, Korkmaz ve Işı1k, 2010; Güney ve Özkoç, 2014).

Matematiği biçimselleştirme çabalarının (Formalist Akım) etkili öncüsü David Hilbert'tir (1862-1943). Biçimselci yaklaşım, Gödel Teoremleri ile de sarsılmış olmasına karşın, pür matematiğin en önemli karakteristiğini sergiler; akıl yürütmelere karışabilecek 
mantık dışı etkenleri ortadan kaldırarak paradokslara düşmeyi önler; sezginin yol açabileceği yanlış bilgilenmeleri ortadan kaldırır. Tam biçimsellik (formalizm) akımının temel prensipleri: 1. Tamlık (sistemde bulunan her geçerli formülün, sonlu bir formel çıkarım dizisi ile aksiyomlardan elde edilebilmesi), 2. Tutarlılık (bir teorem ve bunun zıddının aksiyomlardan çıkarılamaması) ve 3. Obje dil (asıl konunun işlendiği dil) -meta dil (asıl konuya dışardan bakarak onun hakkında konuşulan dil) ayırımının kesin çizgilerle belirlenip, sistem içinde geçen mantık kuralları, tanımlar, varsayımlar ve ispatların, çapraşıklık (muğlaklık) ve sezgiye asla yer vermeden, matematiğin evrensel simgelerinin kullanıldığı, obje diliyle ifade edilmeleri zorunluluğu olarak özetlenebilir. Formalist okulun, matematiğe bir çekidüzen verme yolundaki tam biçimselleştirme çabalarının yerindeliği, büyük ölçüde kabul görmüştür. Formalistler, matematiği içinde saklı (imalı, sezgisel, şüpheli, çapraşık...) hiçbir kayıt bulunmayan, birbirleriyle ilişkileri önceden kesin olarak saptanmış bir simgeler sistemi haline getirmeyi amaçlar. Tüm matematiksel deyim ve kavramlar tanımlandıktan sonra bunlara simgesel bir karşılık verilir. Bu sağlandıktan sonra artık salt matematiksel sistem, bir araya gelişleri ve nasıl kullanılacakları önceden saptanmış ve pür matematik dil ile ifade edilmiş, simge bloklarından ibarettir. Akıl yürütmelerin geçerliliği ya da geçersizliği simgelerin karşılık geldiği terimlerin özel anlamlarından (ya da çağrıştırabileceği olası anlamlardan) bağımsızdır. Varsayımlardan hareketle yeni bilgilere ulaşmak, bir simgeler zincirini, başka bir simgeler zincirine dönüştürmekten ibarettir. Ortaya çıkan sembol zincirleri, yersiz ve yanlış bazı anlamalara yer vermeyecek şekilde, bir örgü gibi işlenerek dikkatle bir araya getirilmiş simgelerden oluşan "sanatsal" soyut tasarımlardır. Biçimsellik tam olarak gerçekleştiğinde, daha önce karşılaşılan ya da karşılaşılabilecek olası tutarsızlık ve çözümsüzlük nedenleri ortadan kalkar; üstelik hangi dili konuşursa konuşsun herkesçe aynı anlama gelen bir evrensel düşünsel sistem ortaya koyulmuş olur. Matematiğe özgü kesinlik dakiklik ve evrenselliği, tam anlamıyla ancak biçimsellik gerçekleştirebilir. Biçimsellik, matematiğin "az sayıda varsayımdan hareketle, çok sayıda yeni ve güvenilir bilgilere ulaştıran en üstün bilimsel disiplin" olduğu düşüncesini pekiştirmiştir. Daha önce ele alınmış bulunan fakat birçok aşamada sezgiye yer veren ve geçişler arasında bazı muğlaklıklar bulunduran birçok matematiksel araştırma konusu, formalistler tarafindan sağlam aksiyomatik temellere oturtulmuştur. "Bilimler, daha güvenilir olmak için daha çok matematik kullanmalıdır" anlayışı artık iyice yerleşmiş ve okullarda da matematik eğitiminin, yüzyıllardır ilk sırada olan yeri adeta sabitlenmiştir. Ayrıca bunun yanında, matematiğin asıl konusunun, varsayımların ya da bunlardan çıkan sonuçların birtakım gerçek olgularla uyumlu olup olmadığını araştırmak değil, fakat ulaşılan bilgilerin (günlük yaşamda kullanabilme kaygısı olmaksızın) başlangıçta varsayılanların zorunlu mantıksal sonuçları olup olmadığını araştırmak olduğu daha iyi anlaşılır olmuştur. Böylece, matematiğin insanoğlunun işine en çok yaradığı tarafının, fizik, mühendislik, vs. alanlarındaki (doğrudan) katkısı değil, fakat onun insanoğlunu doğru düşünebilmeye ve böylece doğru olanı yapabilmeye alıştırabilmek için en uygun antrenman olduğu da daha iyi anlaşılmıştır. Matematik insanları doğru, tutarlı ve dakik düşünmeye alılştıran en organize disiplindir. Güney, matematik eğitimi üzerine yaptığı birçok çalışmasında (Güney, 1993; Güney, 2006; Güney, 2007; Güney, Korkmaz, Işık, 2010; Güney ve Özkoç, 2014) bu alanda yapılan hataları önemle vurgulamıştır. Matematik felsefesinin anlaşılamamasından kaynaklanan bu sorun ancak uzmanlarından alınan iyi bir eğitim ve matematik felsefesi ile matematik mantığını ele alan pek çok eseri (Stevens, 1968; Reichenbach, 1981; Hardy, 1993) incelemekle aş11ır.

\subsection{Matematik Konularının İşlenişinde Karşılaşılan Yanlışlıklara Örnekler}


Önermeler, doğru ya da yanlış kesin bir hüküm bildiren ifadelerdir. Önerme elde etmenin bir yolu da, açık önermelerdeki değişkenleri " $\forall$ " ve " $\exists$ " sembolleriyle gösterdiğimiz ve adına sırasıyla "evrensel" ve "varlıksal" niceleyiciler dediğimiz niceleyiciler ile nicelemektir. Şayet açık önerme çok değişkenli bir açık önerme ise bu açı önermedeki değişkenlerin evrensel ve varlıksal niceleyicilerle nicelenmesi sonucunda çeşitli önermeler elde edilebilir. Bu noktada niceleyicilerin sırasının önemi çoğu kez bilerek ya da bilmeyerek göz ardı edilir. Bu durum ise matematiğin dakikliğini zedeler. Örneğin konu evreni $\mathbb{R} \times \mathbb{R}$ olan $P(x, y)$ : " $x+y=0$ " iki değişkenli açık önermesinin değişkenleri evrensel ve varlıksal niceleyiciler ile nicelendiğinde elde edilen

$$
(\forall x \in \mathbb{R})(\exists y \in \mathbb{R})(x+y=0)
$$

önermesi doğruluk değeri 1 (doğru) olan bir önerme olmasına karşın yine değişkenlerin niceleyicilerle bu kez farklı sirada nicelenmesi ile elde edilen

$$
(\exists y \in \mathbb{R})(\forall x \in \mathbb{R})(x+y=0)
$$

önermesi doğruluk değeri 0 (yanlış) olan bir önermedir. Bu örnek niceleyicilerin sırasının ne kadar önemli olduğunu ortaya koymaktadır. Öte yandan $P(x, y)$ konu evreni $X \times Y$ olan iki değişkenli bir açık önerme olmak üzere

$$
(\exists y \in \mathbb{R})(\forall x \in \mathbb{R})(x+y=0) \rightarrow(\forall x \in \mathbb{R})(\exists y \in \mathbb{R})(x+y=0)
$$

koşullu önermesinin bir gerektirme olduğu göz ardı edilmemelidir. $P(x, y)$, konu evreni $X \times Y$ olan iki değişkenli bir açık önerme olmak üzere

$$
(\exists y \in Y)(\forall x \in X) P(x, y) \rightarrow(\forall x \in X)(\exists y \in Y) P(x, y)
$$

koşullu önermesinin gerektirme oluşu, düzgün sürekli her fonksiyonunun sürekli, düzgün yakınsak her fonksiyon dizisinin noktasal yakınsak ve düzgün denk olan metriklerin topolojik denk olduğunu ispatlarken anahtar görevi görmektedir.

Konu evreni $X \times Y$ olan iki değişkenli bir $P(x, y)$ açık önermenin değişkenlerinin niceleyicilerle nicelenmesinden elde edilen önermeler arasındaki ilişkiler:

(Bloch, 2011).

$$
\begin{array}{ccc}
(\forall x \in X)(\forall y \in Y) P(x, y) & \Leftrightarrow & (\forall y \in Y)(\forall x \in X) P(x, y) \\
\Downarrow & & \Downarrow \\
(\exists x \in X)(\forall y \in Y) P(x, y) & & (\exists y \in Y)(\forall x \in X) P(x, y) \\
\Downarrow & & \\
\Downarrow & \\
(\forall y \in Y)(\exists x \in X) P(x, y) & & (\forall x \in X)(\exists y \in Y) P(x, y) \\
\Downarrow & & \Downarrow \\
(\exists y \in Y)(\exists x \in X) P(x, y) & \Leftrightarrow & (\exists x \in X)(\exists y \in Y) P(x, y)
\end{array}
$$

Tanım: $A \subset \mathbb{R}$ olmak üzere

$$
A, \text { aralık }: \Leftrightarrow[(x, y \in A)(x \leq z \leq y) \rightarrow z \in A] \text { (Güney, 2003a). }
$$


Tanım: $\phi \neq A \subset \mathbb{R}$ küme, $a \in A$ ve $\varepsilon>0$ olmak üzere

$$
B(a, \varepsilon):=\{x|| x-a \mid<\varepsilon, x \in A\} \quad \text { (Bartle ve Sherbert, 2000). }
$$

Tanım: $\phi \neq A \subset \mathbb{R}$ küme, $f: A \rightarrow \mathbb{R}$ fonksiyon ve $x \in \mathbb{R}$ olmak üzere

$x, A$ 'nın yığılma noktas1 $: \Leftrightarrow(\forall \varepsilon>0)((B(a, \varepsilon) \backslash\{x\}) \cap A \neq \phi)$ (Bartle ve Sherbert, 2000).

Tanım: $\phi \neq A \subset \mathbb{R}$ küme, $f: A \rightarrow \mathbb{R}$ fonksiyon, $a \in D(A)$ ve $L \in \mathbb{R}$ olmak üzere

$$
\begin{gathered}
\lim _{x \rightarrow a} f(x)=L: \Leftrightarrow(\forall \varepsilon>0)(\exists \delta>0)(\forall x \in A)(0<|x-a|<\delta \rightarrow|f(x)-L|<\varepsilon) \text { (Bartle ve } \\
\text { Sherbert, 2000). }
\end{gathered}
$$

Tanım: $\phi \neq A \subset \mathbb{R}$ küme, $f: A \rightarrow \mathbb{R}$ fonksiyon, $a \in D(A \cap(a, \infty))$ ve $L \in \mathbb{R}$ olmak üzere

$$
\begin{gathered}
\lim _{x \rightarrow a^{+}} f(x)=L: \Leftrightarrow(\forall \varepsilon>0)(\exists \delta>0)(x \in A \cap(a, a+\delta) \rightarrow|f(x)-L|<\varepsilon) \text { (Bartle ve Sherbert, } \\
\text { 2000). }
\end{gathered}
$$

Tanım: $\phi \neq A \subset \mathbb{R}$ küme, $f: A \rightarrow \mathbb{R}$ fonksiyon, $a \in D(A \cap(-\infty, a))$ ve $L \in \mathbb{R}$ olmak üzere

$$
\begin{gathered}
\lim _{x \rightarrow a_{-}} f(x)=L: \Leftrightarrow(\forall \varepsilon>0)(\exists \delta>0)(x \in A \cap(a-\delta, a) \rightarrow|f(x)-L|<\varepsilon) \text { (Bartle ve Sherbert, } \\
2000) .
\end{gathered}
$$

Tanım: $\phi \neq A \subset \mathbb{R}$ küme ve $f: A \rightarrow \mathbb{R}$ fonksiyon olmak üzere

$$
\begin{gathered}
f,(A ' \text { 'da sürekli } \\
: \Leftrightarrow \\
(\forall a \in A)(\forall \varepsilon>0)(\exists \delta>0)(\forall x \in A)(|x-a|<\delta \rightarrow|f(x)-f(a)|<\varepsilon)
\end{gathered}
$$

(Bartle ve Sherbert, 2000).

Not: $\delta$ sayısının hem $a$ noktasına hem de $\varepsilon$ sayısına bağlı olduğunu gözlemleyiniz.

Tanım: $\phi \neq A \subset \mathbb{R}$ küme ve $f: A \rightarrow \mathbb{R}$ fonksiyon olmak üzere

(Bartle ve Sherbert, 2000).

$$
f,(A \text { 'da }) \text { düzgün sürekli }
$$

$$
(\forall \varepsilon>0)(\exists \delta>0)(\forall a \in A)(\forall x \in A)(|x-a|<\delta \rightarrow|f(x)-f(a)|<\varepsilon)
$$

Not: $\delta$ sayısının sadece $\varepsilon$ sayısına bağlı olduğunu gözlemleyiniz.

Teorem: $\phi \neq A \subset \mathbb{R}$ küme ve $f: A \rightarrow \mathbb{R}$ fonksiyon olmak üzere

$$
f,\left(A^{\prime} \text { da }\right) \text { düzgün sürekli } \Rightarrow f \text {, ( } A^{\prime} \text { da) sürekli. }
$$

İspat. $f,\left(A^{\prime}\right.$ da) düzgün sürekli olsun.

$$
f \text {, ( } A^{\prime} \text { da) düzgün sürekli }
$$

$$
\Rightarrow
$$

$(\forall \varepsilon>0)(\exists \delta>0)(\forall a \in A)(\forall x \in A)(|x-a|<\delta \rightarrow|f(x)-f(a)|<\varepsilon)$ 


$$
\begin{gathered}
(\forall a \in A)(\forall \varepsilon>0)(\exists \delta>0)(\forall x \in A)(|x-a|<\delta \rightarrow|f(x)-f(a)|<\varepsilon) \\
\Rightarrow \text {, }\left(A^{\prime} \text { da) }\right) \text { sürekli. }
\end{gathered}
$$

Örnek: $f(x)=1 /\left(x^{2}+1\right)$ kuralı ile verilen $f: \mathbb{R} \rightarrow \mathbb{R}$ fonksiyonu düzgün süreklidir.

$$
\begin{aligned}
& |f(x)-f(a)|=\left|1 /\left(x^{2}+1\right)-1 /\left(a^{2}+1\right)\right|=|x-a \| x+a| /\left(x^{2}+1\right)\left(a^{2}+1\right) \leq \delta|x+a| / \\
& \left(x^{2}+1\right)\left(a^{2}+1\right) \\
& \leq \delta\left[\left(|x| /\left(x^{2}+1\right)\left(a^{2}+1\right)\right)+\left(|a| /\left(x^{2}+1\right)\left(a^{2}+1\right)\right)\right]<\delta(1+1)=2 \delta \leq \varepsilon
\end{aligned}
$$

olduğundan $\delta$ sayısını sadece $\varepsilon$ sayısına bağlı olarak $0<\delta \leq \varepsilon / 2$ şeklinde seçebileceğimizi gözlemleyiniz.

Örnek: $f(x)=1 / x$ kuralı ile verilen $f: \mathbb{R} \backslash\{0\} \rightarrow \mathbb{R}$ fonksiyonu birçok matematikçi tarafindan süreksiz olarak bilinmesinin aksine sürekli bir fonksiyondur. Ancak düzgün sürekli değildir.

$a \in \mathbb{R} \backslash\{0\}$ için $|x-a|<|a| / 2$ olsun. Bu durumda

$a>0 \Rightarrow|x-a|<a / 2 \Rightarrow-a / 2<x-a<a / 2 \Rightarrow a / 2<x<3 a / 2 \Rightarrow 2 / 3 a<1 / \mathrm{x}<2 / a \Rightarrow 2 / 3|a|<$ $1 /|x|<2 /|a|$

$a<0 \Rightarrow|x-a|<-a / 2 \Rightarrow a / 2<x-a<-a / 2 \Rightarrow 3 a / 2<x<a / 2 \Rightarrow 2 / a<1 / \mathrm{x}<2 / 3 a \Rightarrow 2 / 3|a|<$ $1 /|x|<2 /|a|$

olduğundan

$|1 / x-1 / a|=|(x-a) / x a|=|x-a||| x a|=| x-a|||x||a|<\delta /|x||a|<(\delta /|a|)(2 /|a|)=2 \delta / a^{2} \leq \varepsilon \Rightarrow \delta \leq a^{2} \varepsilon / 2$

elde edilir. Dolayısıyla her $\varepsilon>0$ sayısı için $0<\delta \leq \min \left\{a / 2, a^{2} \varepsilon / 2\right\}$ seçilirse her $x \in \mathbb{R}$ için

$$
|x-a|<\delta \Rightarrow|f(\mathrm{x})-f(a)|<\varepsilon
$$

koşulu sağlanır. O halde $f$ fonksiyonu $a$ noktasında süreklidir. $a \in \mathbb{R} \backslash\{0\}$ olduğundan $f$ fonksiyonu $\mathbb{R} \backslash\{0\}$ 'da süreklidir.

Öte yandan $\varepsilon=1$ olmak üzere her $\delta>0$ sayısı için $x=\delta /(2 \delta+1) \in \mathbb{R} \backslash\{0\}$ ve $a=\delta \in \mathbb{R} \backslash\{0\}$ alınırsa

$$
|x-a|<\delta \wedge|f(\mathrm{x})-f(\mathrm{a})|=2 \geq 1=\varepsilon
$$

koşulu sağlandığından dolayı $f$ fonksiyonu $\mathbb{R} \backslash\{0\}$ 'da düzgün sürekli değildir. 
Örnek: $f(x)=\operatorname{sgn} x$ kuralı ile verilen $f: \mathbb{R} \rightarrow \mathbb{R}$ fonksiyonu süreksiz olmasına karşın aynı kuralla yani $g(x)=\operatorname{sgn} x$ kuralı ile verilen $g: \mathbb{Z} \rightarrow \mathbb{R}$ fonksiyonu süreklidir.

I. Yol: $\varepsilon=1$ olmak üzere her $\delta>0$ sayısı için $x \in(-\delta, \delta) \backslash\{0\}$ alınırsa

$$
|x-0|=|x|<\delta \wedge|f(x)-f(0)|=|f(x)-0|=|f(x)|=1 \geq 1=\varepsilon
$$

koşulu sağlandığından dolayı $f$ fonksiyonu $x=0$ noktasında sürekli değildir. Dolayısıyla fonksiyon sürekli değildir.

II. Yol: $1 / n \rightarrow 0$ fakat $f(1 / n)=1 \rightarrow 1 \neq 0=f(0)$ olduğundan $f$ fonksiyonu $x=0$ noktasında sürekli değildir. Dolayısıyla fonksiyon sürekli değildir.

Not: " $a$ noktasındaki limiti, fonksiyonun $a$ noktasındaki değerine eşitse fonksiyon $a$ noktasında süreklidir." şeklinde verilen tanımın yanlış olduğunu gözlemleyiniz.

Tanım: $G \neq \phi$ küme ve $*: G^{2} \rightarrow G$ fonksiyon olmak üzere

(Maddox,2002).

$$
\begin{gathered}
(G, *) \text { grup } \\
: \Leftrightarrow \\
(\forall x, y, z \in G)(x *(y * z)=(x * y) * z) \\
(\exists \theta \in G)(\forall x \in G)(x * \theta=\theta * x=x) \\
(\forall x \in G)\left(\exists x^{-1} \in G\right)\left(x * x^{-1}=x^{-1} * x=\theta\right)
\end{gathered}
$$

Not: Evrensel ve varlıksal niceleyicilerin sırasına dikkat ediniz.

\section{Çok karșılașılan hatalar:}

\section{Önerme bağlaçları}

Önerme bağlaçlarıyla ilgili tanım ve varsayımlar verilmeden, örnekler üzerinde çalış1larak bunlar keşfedilmeye çalış1liyor.

... " $p, q$ önermeleri birleştirilirken veya bağlacının kullanıldığına dikkat ettiniz mi?.. $\mathrm{Bu}$ durumda veya bağlacı ile bağlanmış iki önerme " $p \vee q$ " olarak yazılır. Yukarıdaki örneklerden yararlanarak $p \vee q$ önermesinin doğruluk tablosunu oluşturalım..."

Aynı şekilde $p \wedge q, p \Rightarrow q, p \Leftrightarrow q$ bileşik önermeleri için de, aksiyom (yani bir kabul) olarak en başta verilmesi gereken doğruluk tabloları -ve hatta terimler- öğrenciye keşfettirilmeye uğraşıllyor!

\section{Niceleyiciler}

Öğrenci yine ne yaptığını ne yapacağını bilmeden örnekler üzerinde çalıştırıldıktan sonra, "bazı", "her" terimlerini daha önceden biliyormuş gibi(!) ve bunlara ait varsayımlar da verilmeden "Bazı niceleyicisi $\exists$ sembolü ile gösterilir... Her niceleyicisi $\forall$ sembolüyle gösterilii" açıklaması yapılıyor. Yine örnekler üzerinde çalışılarak, niceleyicilerin temel teoremi "Yukarıdaki önermelerden anlaşılacağı gibi bazı niceleyicisinin olumsuzu her niceleyicisi, her niceleyicisinin olumsuzu da bazı niceleyicisidir." şeklinde kanıtlanmış oluyor!

\section{İspatlar}


"Teorem: Bir doğal sayının karesi çift sayı ise kendisi de çift sayıdır."

İspat: a çift sayı değilse $\mathrm{a}^{2}$ de çift sayı değildir. a çift sayı değilse $\mathrm{a}=2 \mathrm{n}+1$ şeklinde bir tek sayıdır. Bu durumda, $b$ çift sayı ise $b=2 \mathrm{~m}$ olacak şekilde bir $\mathrm{m}$ doğal sayısı vardır." ve masal devam ediyor!

Başka biri:

"Teorem: $\forall x \in \mathbb{R}$ için, $(x-3) .(x+3)=\left(x^{2}-9\right)$

$x$ değişkenine farklı değerler vererek aşağıdaki tabloda ki noktalı yerleri doldurunuz..." üç-beş denemeden sonra eşit çıktı öyleyse eşit(!) vay vay!

"Teorem: $\forall x \in \mathbb{R} \Rightarrow x \leq x^{2}$

(Yine değerler vererek önce doğru bulunuyor.) dördüncü denemede $x=1 / 2$ için yanlış, o halde önerme yanlıştır" Neden teorem diye başladınız?! Bunlar birçok doğru örnek arasından seçilmiş hatalı olanlar değildir. Ne yazık ki kitabın tümü bu "minvaldedir."

\section{Kümeler}

İşlenilen mantık konusu hiç kullanılmadan küme ile ilgili eşitlik, alt küme, birleşim, kesişim vb. kavramlar öğrenciye buldurulmaya çalış1lıyor. Birleşim ve kesişim ile ilgili açıklamaya bakınız: " $A$ ve $B$ herhangi iki küme olmak üzere bu iki kümenin ortak elemanlarının oluşturduğu kümeye $A$ ile $B$ kümelerinin kesişim kümesi, tüm elemanlarının oluşturduğu kümeye de $A$ ile $B$ kümelerinin birleşim kümesi denir. Bu durumda, $K=A \cap B$, $L=A \cup B$ gösterimlerinin doğru olup olmadığını araştırınız.". Acaba nedir nedir?

$$
A \cap B=\{x \mid x \in A \wedge x \in B\} \text { ve } A \cup B=\{x \mid x \in A \vee x \in B\}
$$

tanımları çok mu ağır geliyor da bunlar öğrenciye verilmek istenmiyor. Bu şekilde tüm teoremler geçiştirilerek "sıfır mantıkla" devam ediliyor. Doğru yazılmış bir tek sayfa bulabilene aşk olsun!

\section{Kartezyen Çarpım}

Sayısal olmayan veya elemanları arasında bir sıralamanın söz konusu olmadığı ve elemanları için gerçel eksen üzerinde birtakım noktaların söz konusu olmadığı kümeler arasındaki bağıntıların kartezyen düzlemde grafikleri çiziliyor! Bağıntılar ve özellikleri yine mantıksızlıklarla dolu olarak anlatılıyor ve sayısal olmayan bağıntılar da analitik düzlemde gösterilmeye kalk1liyor.

\section{Sabit Fonksiyon}

" $f$ sabit fonksiyon ise $f: \mathbb{R} \rightarrow \mathbb{R}, \forall x \in \mathbb{R}$ için $f(x)=c(c \in \mathbb{R})$ şeklinde ifade edilir."

Sayfa sinırlaması nedeniyle, hemen tüm kitap boyunca süren, yanlış sorular, tanımın kanıtı(!), deneme yöntemiyle ispat(!), yanlış bilgiler, yanlış simge kullanımları, kartezyen düzlemin yanlış kullanımı ve bir yığın yanlışlığa yer veremiyoruz.

\section{Sayılabilirlik}

Çoğu zaman sayılabilirlik sonluluk ile karıştırılıyor. Süreklilik tanımı, limit tanımı yanlış ya da eksik veriliyor.

\section{Boșluk ve evrensellik ile ilgili düșünceler:}


Boş küme vardır, olmayan onun elemanıdır!.. Boş kümede evrenin hiçbir elemanı yoktur ama evrenin alt kümelerinden biri de boş kümedir. Eğer evreni önemsiyorsanız, boş kümeyi önemsemelisiniz! Çünkü boş küme, evren ve sonsuzluk birbirleriyle sıkı ilişki içindedir:

1. Boş kümenin her elemanı sonsuzdur.

$$
x \in \phi \Rightarrow x=\infty
$$

İspat. Besbelli !..

Not 1: $(0 \Rightarrow p(x)) \equiv 1$

2. Bir $(E, d)$ metrik uzayında boş kümenin çapı (eksi) sonsuzdur.

İspat.

$$
(E, d) \text { metrik uzay } \Rightarrow d(\phi)=-\infty \text {. }
$$

$$
d(\phi)=\sup \{d(x, y) \mid x, y \in \phi\}=\sup \phi=\min \phi^{\ddot{u}}=\min \mid \mathbb{R}=\min \mathbb{R} \cup\{-\infty,+\infty\}=-\infty .
$$

Not 2: Bir $(E, d)$ metrik uzayında bir $A$ kümesinin çapı ikişer ikişer elemanları arasındaki uzaklıklar kümesinin supremumuna $\operatorname{denir} ; \mathrm{d}(A)$ ile gösterilir.

$$
\begin{gathered}
(E, d) \text { metrik uzay } \\
A \subset E \\
\Rightarrow \\
\mathrm{d}(A):=\sup \{\overrightarrow{d(x, y) \mid x, y \in A\}}
\end{gathered}
$$

3. $\operatorname{Bir}(E, d)$ metrik uzayında boş küme sınırsızdır.

$$
(E, d) \text { metrik uzay } \Rightarrow \mathrm{d}(\phi) \notin \mathbb{R}
$$

İspat. 2’den.

Not 3: Bir $(E, d)$ metrik uzayında çapı sonlu olan bir kümeye (çapı bir gerçel sayı olan bir kümeye) sınırlı küme, aksi halde yani çapı artı sonsuz veya eksi sonsuz olan bir kümeye sinırsız küme denir.

$$
\begin{aligned}
&(E, d) \text { metrik uzay } \\
& A \subset E \\
& \Rightarrow \\
& A \text { sinırl }: \Leftrightarrow \mathrm{d}(A) \in \mathbb{R} \\
& A \text { sinırsiz }: \Leftrightarrow \mathrm{d}(A) \in \mathbb{R} \backslash \mathbb{R}=\{+\infty,-\infty\}
\end{aligned}
$$

4. $\operatorname{Bir}(E, \alpha)$ sıra yapısında boş küme hem alttan hem de üstten sınırlıdır

$$
\begin{aligned}
(E, \alpha) \text { poset } & \\
& \Rightarrow \\
\phi^{u} \neq \phi & \wedge \phi^{a} \neq \phi \\
& \Leftrightarrow \\
(\exists x \in E, \forall y \in \phi, y \alpha x) & \wedge(\exists x \in E, \forall y \in \phi, x \quad \alpha \quad y)
\end{aligned}
$$


İspat.

$$
\phi^{i u}=\{x \mid y \in \phi \Rightarrow y \alpha x\}=E \neq \phi \text { ve } \phi^{a}=\{x \mid y \in \phi \Rightarrow x \alpha \quad y\}=E \neq \phi
$$

Not 4: Bir $(E, \alpha)$ sira yapısında (poset, kafes, zincir, vs.) bir $A$ kümesinin tüm elemanlarından büyük olan bir elemana, $A$ kümesinin bir üst sınırı denir; $A$ kümesinin tüm üst sınırlarının kümesi $A^{\ddot{u}}$ ile gösterilir. $A$ kümesinin tüm elemanlarından küçük olan bir elemana, $A$ kümesinin bir alt sınırı denir; $A$ kümesinin tüm alt sınırlarının kümesi $A^{a}$ ile gösterilir. $A$ kümesinin en az bir üst sınırı varsa (yani $A^{u ̈}$ boş değilse) $A$ 'ya üstten sınırlı denir; en az bir alt sınırı varsa (yani $A^{a}$ boş değilse) $A^{\prime}$ ya alttan sınırlı denir.

$$
\begin{gathered}
(E, \alpha) \text { poset } \\
A \subset E \\
\Rightarrow \\
A^{u}:=\{x \mid y \in A \Rightarrow y \alpha x\} \\
A^{a}:=\{x \mid y \in A \Rightarrow x \alpha y\}
\end{gathered}
$$

$A$ üstten sinırlı

$$
\begin{gathered}
: \Leftrightarrow \\
A^{i u} \neq \phi \\
: \Leftrightarrow \\
\exists x \in E, \forall y \in A, y \alpha x
\end{gathered}
$$

$$
\begin{gathered}
A \text { alttan sinirl } 1 \\
: \Leftrightarrow \\
A^{a} \neq \phi \\
: \Leftrightarrow \\
\exists x \in E, \forall y \in A, x \quad \alpha \quad y
\end{gathered}
$$

5. $\operatorname{Bir}(E, \alpha)$ sıra yapısında boş küme sınırlıdır.

$$
(E, \alpha) \text { poset } \Rightarrow \phi \text { sinırlı }
$$

İspat. Teorem 4 ve Not 5.

Not 5: Bir $(E, \alpha)$ sira yapısında bir $A$ kümesi hem üstten hem de alttan sinırlyysa buna sinırlı küme denir; aksi halde sınırsız denir.

$$
\begin{gathered}
(E, \alpha) \text { poset } \\
A \subset E \\
\Rightarrow \\
A \text { sinırl } \\
: \Leftrightarrow \\
A^{u ̈} \neq \phi \wedge A^{a} \neq \phi \\
A \text { sinırsiz } \\
: \Leftrightarrow \\
A^{a}=\phi \vee A^{u}=\phi
\end{gathered}
$$

6. Boş ailenin kesişimi tüm evrendir. 


$$
\cap \phi=E
$$

İspat.

$$
\cap \phi=\{x \mid A \in \phi \Rightarrow x \in A\}=E
$$

Not 6: Bir $X$ evrenin alt kümelerinden oluşan bir ailenin kesişimi aileye ait her kümede bulunan elemanların oluşturduğu kümeye denir; bir ailenin birleşimi de bu ailedeki kümelerden en az birine ait olan elemanlardan oluşan kümeye denir. $\mathcal{A}$ ailesinin kesişimi $\cap \mathcal{A}$ ile birleşimi $\cup \mathcal{A}$ ile gösterilir.

$$
\begin{gathered}
\mathcal{A} \subset 2^{X} \\
\Rightarrow \\
\cap \mathcal{A}:=\{x \mid \forall A \in \mathcal{A}, x \in A\}=\{x \mid A \in \mathcal{A} \Rightarrow x \in A\} \\
\cup \mathcal{A}:=\{x \mid \exists A \in \mathcal{A}, x \in A\}
\end{gathered}
$$

7. Genişletilmiş gerçel sayıların alışılmış posetinde, boş kümenin supremumu artı sonsuz, infimumu eksi sonsuzdur.

$$
(\mid \mathbb{R}, \leq) \Rightarrow \inf \phi=\infty, \sup \phi=-\infty
$$

İspat.

$$
\begin{gathered}
\sup \phi=\min \phi^{\ddot{u}}=\min \mid \mathbb{R}=\min \mathbb{R} \cup\{-\infty,+\infty\}=-\infty \\
\inf \phi=\max \phi^{a}=\max \mid \mathbb{R}=\max \mathbb{R} \cup\{-\infty,+\infty\}=\infty .
\end{gathered}
$$

Not7: Bir $(E, \alpha)$ sıra yapısında bir kümenin supremumu üst sınırlarının minimum elemanı, infimumu alt sınırlarının maksimum elemanıdır.

$$
\begin{gathered}
(E, \alpha) \text { poset } \\
A \subset E \\
\Rightarrow \\
\sup A:=\min A^{\vec{u}}, \inf A:=\max A^{a}
\end{gathered}
$$

8. Bir $(E, d)$ metrik uzayında bir noktanın boş kümeye uzaklığı sonsuzdur.

İspat.

$$
((E, d) \text { metrik uzay })(x \in E) \Rightarrow \mathrm{d}(x, \phi)=\infty
$$

$$
\mathrm{d}(x, \phi)=\inf \{d(x, y) \mid y \in \phi\}=\inf \phi=\infty .
$$

Not 8: Bir $(E, d)$ metrik uzayında bir $x$ noktasının bir $A$ kümesine uzaklığı, $x$ 'in $A$ 'nın noktalarına uzaklıklar kümesinin infimumuna denir; $\mathrm{d}(x, A)$ ile gösterilir.

$$
\begin{gathered}
(E, d) \text { metrik uzay } \\
A \subset E
\end{gathered}
$$




$$
\begin{gathered}
x \in E \\
\Rightarrow \\
\mathrm{d}(x, A):=\inf \{d(x, y) \mid y \in A\}
\end{gathered}
$$

9. Bir $(E, \tau)$ topolojik uzayında boş kümenin dışı ve tümleyeni tüm evrendir.

$$
(E, \tau) \text { topolojik uzay } \Rightarrow \phi^{d}=E=\backslash \phi
$$

İspat.

$$
\phi^{d}=(\phi)^{\mathrm{o}}=E^{\mathrm{o}}=E
$$

Not 9: $\operatorname{Bir}(E, \tau)$ topolojik uzayında bir $A$ kümesinin içi diye, en az bir komşuluğu $A$ kümesi tarafından kapsanan noktaların kümesine denir; $A^{0}$ ile gösterilir. Bir kümenin dış1 diye, evrendeki en az bir komşuluğu kümenin tümleyeni tarafından kapsanan noktalarının kümesine denir; $A^{d}$ ile gösterilir. Buna göre bir kümenin dışı tümleyeninin içine eşittir.

$$
\begin{gathered}
(E, \tau) \text { topolojik uzay } \\
A \subset E \\
\Rightarrow \\
A^{\mathrm{o}}=\{x \mid(\exists U \in \mathcal{U}(x))(U \subset A)\} \\
A^{d}=\{x \mid(\exists U \in \mathcal{U}(x))(U \subset \backslash A)\} \\
A^{d}=(\backslash A)^{\mathrm{o}}
\end{gathered}
$$

10. En az bir metrik topolojik uzayda sınırlı fakat sınırı boş olan en az bir alt küme vardır.

$$
\exists\left(E, \tau_{d}\right) \text { metrik topolojik uzay, } \exists A \subset E, A^{s}=\phi, \mathrm{d}(A)=\infty
$$

İspat. $E=[0,1)$ alışılmış topolojiye relatif topolojiyle donatılırsa $A^{s}=\phi, \mathrm{d}(A)=1$

Not 10: Bir $(E, \tau)$ topolojik uzayında bir $A$ kümesinin sınırı, her komşuluğunda hem $A$ 'da hem de $\backslash A$ ' da bulunan noktaların kümesidir; $A^{s}$ biçiminde gösterilir.

$$
\begin{gathered}
(E, \tau) \text { topolojik uzay } \\
A \subset E \\
\Rightarrow \\
A^{s}:=\{x \mid(\forall U \in \mathcal{U}(x))(U \cap A \neq \phi \wedge U \cap(\backslash A) \neq \phi)\}
\end{gathered}
$$

11. Sınırlı olsun sınırsız olsun (yani çapı sonlu olsun sonsuz olsun) her metrik topolojik uzayın sınırı boş kümedir.

$$
\left(E, \tau_{d}\right) \text { metrik topolojik uzay } \Rightarrow E^{s}=\phi
$$

İspat. Not 10.

Ayrica

12. $\exists(E, \tau)$ topolojik uzay, $\exists A \subset E, \aleph_{0} \leq\left|A^{s}\right|, \mathrm{d}(A)<\infty$.

13. $\exists(E, \tau)$ topolojik uzay, $\exists A \subset E, \aleph_{\circ} \leq|A|, A^{0}=A^{d}=\phi$.

14. $\exists(E, \tau)$ topolojik uzay, $\exists A \subset E, \aleph_{0} \leq|A|, A^{s}=\phi$.

15. $\exists(E, \tau)$ topolojik uzay, $\exists A \subset E,|A|<\aleph_{0}, \aleph_{0} \leq|\bar{A}|$.

16. $\phi: \phi \rightarrow \phi$ bağıntısı (boş bağıntı), yansıyan, simetrik, geçişken. 
(Güney, 2003b).

Sürekliliğe Dair: Şunu anlatamadık... Çok sık olarak doğru bir önerme sanılıp kullanılan, "Bir fonksiyon tanımlı olmadığı bir noktada süreksizdir." ifadesi anlamsızdır. Bir fonksiyonun bir noktada sürekliliği de süreksizliği de bu fonksiyonun tanım kümesindeki noktalar için söz konusudur (tanımlıdır). Tanımlı olmadığı bir noktada fonksiyondan eser yoktur! Olmayan bir şeyin sürekliliği de, süreksizliği de yahut başka bir şeyi de olmaz!..

\section{Sonuç}

Matematik derslerinin temel amacı öğrencilere doğru ve mantıklı düşünme alışkanlığ kazandırmaktır. $\mathrm{Bu}$ nedenledir ki matematik eğitimcileri ve öğretmenleri matematik öğretiminin önemini, matematiğin mantığını, yöntemini, dilini iyi bilmeliler, matematiğin muazzam gücünü ve güzelliğini öğrencilere hissettirmelidirler. Okullarda matematik derslerinde kullanılacak kitapların seçiminde kavramları doğru ve matematiksel bir dil ile ele almış kaynaklar seçilmelidir. Yalnız matematik dersleri için değil, tüm alan dersleri için yazılan kitapların hazırlanması ve kontrolü alanına hâkim bilim adamlarının ve yetkin kişilerin denetimi altında yapılmalıdır. Öğrencilere yanlış ve eksik aktarılan her bilgi daha sonra öğrendikleri bilgilerin de akıllarına yanlış ve eksik biçimde yerleşmesine sebep olur. $\mathrm{Bu}$ durum ise öğrencilerin doğru düşünmelerini, doğru kararlar verebilmelerini olumsuz yönde etkileyerek, hem tüm eğitim hayatlarını hem de yaşamlarını tehdit eder. Öğretmenler de bilinçli olup kullanılacak ders kitaplarını dikkatle incelemeli ve matematiği matematikten başka bir şeye çeviren tüm eser, yöntem ve anlatımlardan kesinlikle uzak durmalıdırlar.

\section{Kaynakça}

Bartle, R.G., Sherbert, D.R. (2000). Introduction To Real Analysis, Third Edition. John Wiley\&Sons, Inc.

Bloch, E.D. (2011). Proofs and fundamentals, A First Course In Abstract Mathematics. Second Edition, Springer.

Güney, Z. (1993). Matematik Ve Eğitimi Üzerine, Buca Ĕg. Fak. Ĕg. Bil. Der. D.E.Ü.

Güney, Z. (2003a). Metrik Ve Topolojik Formüller (Ders Kitabı). Muğla: MSKÜ Yayınları.

Güney, Z. (2003b). Boşluk, Sonsuzluk Ve Biçimcilik Üzerine. I. Ulusal Mantık, Matematik Ve Felsefe Sempozyumu, 26-28 Eylül 2003, Çanakkale: İstanbul Kültür Üniversitesi.

Güney, Z. (2006). Ortaöğretim Matematik Ders Kitaplarındaki Olumsuzluklar Üzerine. VII. Ulusal Matematik Eğitimi Kongresi. Ankara: Gazi Üniversitesi.

Güney, Z. (2007). Lise Matematik Ders Kitaplarındaki Kavram Ve Yöntem Yanılgıları. Ulusal Teknik Eğitim Mühendislik Ve Eğitim Bilimleri Genç Araştırmacılar Sempozyumu. İzmit: Kocaeli Üniversitesi.

Güney, Z. (2013). Maatematiksel zihin sporu, Türk daması. Muğla: hamle matbaacllık. Güney, Z., Korkmaz, N., Işı, O.R. (2010). Matematik Öğretiminde Yapılandırmacı Yaklaşımın Sakıncaları. IX. Ulusal Fen Bilimleri Ve Matematik Eğitimi Kongresi, 23-25 Eylül 2010, İzmir: Buca.

Güney, Z., Özkoç M. (2014). Matematikte Doğru Bilinen Bazı Yanlışlar Üzerine. Matematik Sempozyumu. Karabük Üniversitesi.

Güney, Z., Paşalı, A.S., Özsot, N., Koçak, Z.F. (2013). Türk Daması Ve Geleneksel Oyunlar. Ankara: Hacettepe Üniversitesi.

Hardy G.H. (1993). Bir Matematikçinin Savunması (N. Arık, Çev.). TÜBİTAK.

King, J.P. (1999). Matematik Sanatı (N. Arık, Çev.). TÜBİTAK. 
Maddox, R.B. (2002). Mathematical thinking and writıng, A Transition To Abstract Mathematics. Harcourt/Academic Press.

Reichenbach, H (1981). Bilimsel Felsefenin Doğuşu. Remzi Kitabevi.

Stevens, S.S. (1968). Matematik Ölçme Ve Psikofizik. Ankara.

\begin{tabular}{|c|c|}
\hline Zekeriya GÜNEY & $\begin{array}{l}\text { Prof. Dr., Muğla Sttkı Koçman Üniversitesi, Eğitim } \\
\text { Fakültesi, Ortaöğretim Fen/Matematik Alanlar Eğitimi } \\
\text { Bölümü, Matematik Eğitimi ABD, } 48000 \text { Menteşe/MUĞLA } \\
\text { e-posta: zguney@mu.edu.tr }\end{array}$ \\
\hline Murad ÖZKOÇ & $\begin{array}{l}\text { Yrd. Doç. Dr., Muğla Sitkı Koçman Üniversitesi, Fen } \\
\text { Fakültesi, Matematik Bölümü, } 48000 \text { Menteşe/MUĞLA } \\
e \text {-mail: murad.ozkoc@,mu.edu.tr }\end{array}$ \\
\hline Nebiye KORKMAZ & $\begin{array}{l}\text { Yrd. Doç. Dr., Muğla Sttkı Koçman Üniversitesi, Eğitim } \\
\text { Fakültesi, İlköğretim Bölümü, Matematik Eğitimi ABD, } \\
\text { 48000-Menteşe/MUĞLA } \\
e \text {-mail: nkorkmaz@mu.edu.tr }\end{array}$ \\
\hline
\end{tabular}

